\title{
SPECIES-SPECIFIC FOREST VARIABLE ESTIMATION USING NON-PARAMETRIC MODELING OF MULTI-SPECTRAL PHOTOGRAMMETRIC POINT CLOUD DATA
}

\author{
J. Bohlin*, J. Wallerman, H. Olsson, J. E. S. Fransson \\ Swedish University of Agricultural Sciences, Department of Forest Resource Management \\ SE-901 83 Umeå, Sweden, Jonas.Bohlin@slu.se \\ Commission VIII, WG VIII/7
}

KEY WORDS: Forestry, photogrammetry, estimation, inventory, spectral, stereoscopic, point cloud, mapping.

\begin{abstract}
The recent development in software for automatic photogrammetric processing of multispectral aerial imagery, and the growing nation-wide availability of Digital Elevation Model (DEM) data, are about to revolutionize data capture for forest management planning in Scandinavia. Using only already available aerial imagery and ALS-assessed DEM data, raster estimates of the forest variables mean tree height, basal area, total stem volume, and species-specific stem volumes were produced and evaluated. The study was conducted at a coniferous hemi-boreal test site in southern Sweden (lat. $58^{\circ} \mathrm{N}$, long. $13^{\circ} \mathrm{E}$ ). Digital aerial images from the Zeiss/Intergraph Digital Mapping Camera system were used to produce 3D point-cloud data with spectral information. Metrics were calculated for 696 field plots ( $10 \mathrm{~m}$ radius) from point-cloud data and used in $k$-MSN to estimate forest variables. For these stands, the tree height ranged from 1.4 to $33.0 \mathrm{~m}$ (18.1 m mean), stem volume from 0 to $829 \mathrm{~m}^{3} \mathrm{ha}^{-1}\left(249 \mathrm{~m}^{3} \mathrm{ha}^{-1} \mathrm{mean}\right)$ and basal area from 0 to $62.2 \mathrm{~m}^{2} \mathrm{ha}^{-1}\left(26.1 \mathrm{~m}^{2} \mathrm{ha}^{-1}\right.$ mean), with mean stand size of 2.8 ha. Estimates made using digital aerial images corresponding to the standard acquisition of the Swedish National Land Survey (Lantmäteriet) showed RMSEs (in percent of the surveyed stand mean) of $7.5 \%$ for tree height, $11.4 \%$ for basal area, $13.2 \%$ for total stem volume, $90.6 \%$ for pine stem volume, 26.4 for spruce stem volume, and $72.6 \%$ for deciduous stem volume. The results imply that photogrammetric matching of digital aerial images has significant potential for operational use in forestry.
\end{abstract}

\section{Introduction}

\subsection{Motivation}

In Nordic boreal forestry, aerial imagery has the potential to gain increasing importance as a source of data for detailed spatial estimates of forest variables. This is due to the recent evolution of new and efficient algorithms for 3D data generation using automatic matching of stereo imagery and photogrammetric derivation of tree canopy height data. Furthermore, the growing availability of accurate DEM data is a key component in the use of 3D data for forest mapping purposes. National level acquisition of Airborne Laser Scanning (ALS) to produce accurate Digital Elevation Models (DEMs) has been completed in several European countries. In Sweden and Finland, among other countries, is ALS mapping ongoing. Furthermore, Swedish National Land Survey (Lantmäteriet) utilizes two Zeiss/Intergraph Digital Mapping Camera (DMC) systems to routinely map the country at an annual rate of one third of the area. Hence, DMC data are available nation-wide at a low cost, providing spectral data as well as $3 \mathrm{D}$ data of the vegetation canopy.

\subsection{Background}

Forest companies commonly utilize ALS-assessed forest information, estimated primarily using area-based methods (Magnussen och Boudewyn, 1998; Næsset, 2002b; Næsset et al., 2004). In boreal forest, these methods deliver stand level estimation accuracies in terms of Root Mean Square Error (RMSE) for tree height typically in the range of 2.5-13.6\% (in

\footnotetext{
* Corresponding author.
}

percent of the surveyed mean), stem diameter in the range of 5.9-15.8\% and stem volume 8.4-16.6\% (Næsset et al., 2004; McRoberts et al., 2010). This generally outperforms traditional sources for forest management data, such as subjective field estimation. Using subjective field methods RMSE of 15-25\% and about $10 \%$ RMSE for stem volume and tree height, respectively, was achieved (Ståhl, 1988; Ståhl, 1992). Næsset (2002a) used scanned analog high-resolution ( $0.19 \mathrm{~m}$ pixel size) aerial images to derive 3D data using photogrammetric image matching. Ground elevation was assessed using manual photo-interpretation of the images viewed in stereo in a limited number of locations with visible ground and interpolated to full spatial cover. At their test site in Norway, tree height was estimated for forest stands using regression with standard error ranging from $0.9 \mathrm{~m}$ to $2.1 \mathrm{~m}$, which is similar to accuracy achieved using photointerpretation. In Sweden, using standard aerial imagery and an accurate DEM, Bohlin et al., (2012) estimated forest variables from DMC imagery. For tree height, stem volume, basal area the result shows RMSEs of $8.8 \%, 13.1 \%$ and $14.9 \%$, respectively, at stand level.

In forest management planning, tree-species information is important. Therefore, extending the ALS methodology by adding spectral data to achieve tree species-specific estimates using various frameworks such as non-parametric methods like $k$-MSN; Packalén and Maltamo (2007), Packalén et al. (2009) reported plot level RMSE accuracies for pine volume, spruce volume and deciduous volume of $33-52 \%, 56-63 \%$ and $84-$ $103 \%$, respectively. And for stand level accuracy RMSEs, pine volume $28 \%$, spruce volume $32 \%$ and deciduous volume $62 \%$ (Packalén and Maltamo, 2007). 


\subsection{Aim}

This study aims to investigate the possibilities to estimate species-specific (pine, spruce and deciduous trees) mean stem volume $(V)$, mean basal area $(B A)$ and basal-area-weighted mean tree height $(H)$ at stand level using spectral and 3D data from the DMC sensor in combination with ALS DEM data. This was performed using the $k$-MSN estimation framework, as described by Packalén et al. (2009).

\section{Materials}

\subsection{Study Area and Field Data}

The study area is part of the Remningstorp forest estate, which is situated at $58^{\circ} 30^{\prime} \mathrm{N}, 13^{\circ} 40^{\prime} \mathrm{E}$ (Figure 1). The estate is managed for timber production, and has relatively flat terrain. The forest is mainly dominated by Norway Spruce (Picea abies), Scots Pine (Pinus sylvestris) and Birch species (Betula spp.).

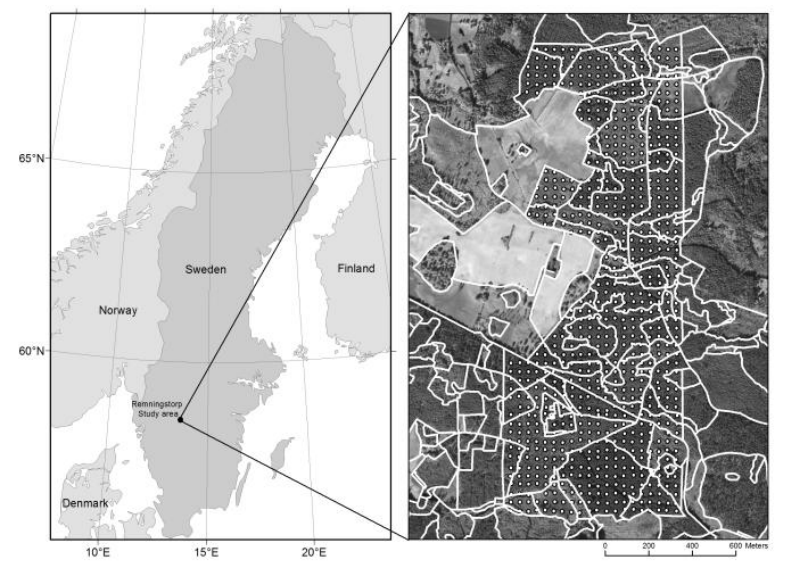

Figure 1. The Remningstorp test site (left) and orthophoto of the area including field plot positions and stand borders (right).

Circular field plots (10 m radius) were objectively surveyed between 2004 and 2005 using a dense grid sample design, which was a regular quadratic grid with $40 \mathrm{~m}$ spacing between adjacent plots over the $1.0 \mathrm{~km}$ by $2.3 \mathrm{~km}$ central part of the estate. The origin of the grid was allocated randomly. Each plot was surveyed using the methods and state-estimating models of the Forest Management Planning Package (Jonsson et al., 1993). For plots with mean tree height less than $4 \mathrm{~m}$ or basalarea-weighted mean stem diameter at breast height (i.e., $1.3 \mathrm{~m}$ above ground) less than $5 \mathrm{~cm}$, height and species of all saplings and trees were recorded. For the remaining plots, callipering of all trees at breast height including only trees greater than $5 \mathrm{~cm}$ in diameter, and sub-sampling of trees to measure height and age, were performed. Heights of remaining callipered trees on the plots were estimated using models developed by Söderberg (1992) relating tree height to diameter. Plot location was measured using differential GPS producing sub-meter accuracy. Correction of the forest growth between the surveys and the date of aerial image acquisition was made by forecasting the forest state at each plot to the year 2005, using single tree growth models (Söderberg, 1986). In total, 696 plots were surveyed in 69 stands, delineated by a professional photointerpreter using a digital photogrammetric workstation. At these plots the tree height range was $1.4-33.0 \mathrm{~m}$ (with an average of $18.1 \mathrm{~m})$, stem volume $0-829 \mathrm{~m}^{3} \mathrm{ha}^{-1}\left(249 \mathrm{~m}^{3} \mathrm{ha}^{-1}\right)$ and basal area 0.0-62.2 $\mathrm{m}^{2} \mathrm{ha}^{-1}\left(26.1 \mathrm{~m}^{2} \mathrm{ha}^{-1}\right)$.

\subsection{Remote sensing data}

ALS data were captured in September 2008 by the TopEye Mk II system with a wavelength of $1064 \mathrm{~nm}$ and a $25 \mathrm{~cm}$ footprint. This system was operated at a flight altitude of $250 \mathrm{~m}$ a.g.l., resulting in an average density of 7 pulses per square meter. Following the acquisition, each return was classified as a ground or non-ground return using the progressive Triangular Irregular Network (TIN) densification method (Axelsson, 1999, 2000) implemented in the TerraScan software (Soininen, 2004). Then, a raster DEM with a $0.5 \mathrm{~m}$ by $0.5 \mathrm{~m}$ cell size was created by assigning each cell the mean height value of ground returns within the cell. Height values of raster cells without ground returns were TIN interpolated using neighboring DEM cells.

The digital aerial images were acquired on 28 June 2005 (at $9.40 \mathrm{~h}$ local time) with the DMC system operated by Lantmäteriet. It consists of four panchromatic and four spectral camera heads. The four panchromatic images are stitched into one, and merged with the spectral images to create one pansharpened virtual image with $7680 \times 13824$ pixels (Hinz et al., 2001). Eleven images were acquired, at $4800 \mathrm{~m}$ a.g.l. using one flight strip with $60 \%$ along-track image overlap. As result, Ground Sampling Distance for the image block is about $0.48 \mathrm{~m}$. Images were aerial triangulated using bundle adjustment and radiometrically corrected by Lantmäteriet.

\section{Methods}

\subsection{Photogrammetric matching and Classification}

Then, photogrammetric image matching was performed using the Match-T DSM software version 5.3.1 (Anon, 2011) to produce a point cloud data set. This was done by sequential multi-matching (Lemaire, 2008), where both least squares and feature-based matching were combined. Following Packalén and Maltamo (2007), the point cloud was colorized by ray tracing each point back to the image plane coordinates, using the exterior and interior orientations of the images. Each point was assigned its mean spectral value from all images the point is visible in, resulting in a NIR, Red and Green colored point cloud. Finally, the point cloud height values were normalized by subtracting the ALS DEM.

Based on the spectral data, the tree species class corresponding to each point was estimated. This was performed by supervised classification using plots with uniform species composition, i.e. plots where more than $95 \%$ of the field surveyed volume constituted of pine, spruce or deciduous trees $(40,351$ and 18 plots, respectively) as training data. All points below $0.5 \mathrm{~m}$ were regarded as ground points and therefore removed prior to the classification. Species classification of the point cloud was made using quadratic discriminant analysis with equal priors.

\subsection{Estimation of forest variables}

Ten metrics summarizing the point cloud data, such as height distribution and spatial density characteristics, were calculated from the tree species classified point cloud using the Fusion software package (McGaughey, 2012) developed by US Department of Agriculture Forest Service. These metrics were used as independent variables to estimate the addressed forest 
variables. Point cloud metrics were extracted for both sample plots and wall-to-wall rasters with $18 \mathrm{~m} \times 18 \mathrm{~m}$ cellsize (similar to the sample plot area). Six metrics describing canopy height were used, the percentiles corresponding to the $20,40,60,80$, 90 and 95 quantiles of the point height distribution $\left(p_{20}, p_{40} \ldots\right.$, $\left.p_{95}\right)$. To describe canopy density, the two metrics "Canopy relief ratio" ((mean - $\min ) /(\max -\min ))$ and "percentage of points above Mode" where generated. In addition, the species classified points were used to generate three metrics, one for each species proportion. However, only two of the three species proportion metrics are needed in the model.

The target forest variables: tree height; basal area; pine volume; spruce volume; deciduous volume and total volume were estimated using $k$-MSN, with $k=1$. Stem volume and basal area were logarithmically transformed in order to achieve linear relationships in the canonical correlation transformation. Estimation was done using the YaImpute library in the $\mathrm{R}$ statistical software package (R Development Core Team, 2010) and resulted in raster data sets for the target variables.

\subsection{Accuracy assessment}

Finally, stand-level estimation accuracy was assessed on all stands with six or more plots (to achieve reasonably accurate field surveyed stand level means), resulting in 41 stands. For each stand, the averages of raster cell estimates and averages of measured plot values were calculated. At these stands the tree height range is $3.5-27.9 \mathrm{~m}$ (with an average of $17.6 \mathrm{~m}$ ), stem volume $5.4-558 \mathrm{~m}^{3} \mathrm{ha}^{-1}\left(231 \mathrm{~m}^{3} \mathrm{ha}^{-1}\right)$, basal area $1.6-45.7$ $\mathrm{m}^{2} \mathrm{ha}^{-1}\left(24.9 \mathrm{~m}^{2} \mathrm{ha}^{-1}\right)$ and with mean stand size of 2.8 ha. The results were evaluated in terms of RMSE and bias (in percent of the surveyed stand mean).

\section{Results and discussion}

The results (Table 1, Figure 2) show higher accuracy for the total volume estimates compared to species-specific stem volume estimates, as measured by RMSE in percentage of the surveyed mean. The errors in absolute terms show different relations, though, indicating similar accuracy for all cases (see also Figure 2). This relation is also present for the observed biases.

Table 1. Stand-level accuracy of mean tree height $(H)$, mean basal area $(B A)$, total stem volume $\left(V_{t o t}\right)$ and stem volume by tree species; pine $\left(V_{p}\right)$, spruce $\left(V_{s}\right)$, and deciduous $\left(V_{d}\right)$

\begin{tabular}{lllll}
\hline & RMSE & RMSE $[\%]$ & Bias & Bias $[\%]$ \\
\hline$H$ & 1.32 & 7.45 & 0.23 & 1.3 \\
$B A$ & 2.85 & 11.4 & 0.26 & 1.1 \\
$V_{\text {tot }}$ & 30.6 & 13.2 & 2.5 & 1.1 \\
$V_{p}$ & 25.5 & 90.6 & 2.7 & 9.7 \\
$V_{s}$ & 46.1 & 26.4 & -0.21 & -0.12 \\
$V_{d}$ & 10.6 & 72.6 & -1.6 & -10.6 \\
\hline
\end{tabular}

This study shows that 3D data from the standard aerial image acquisition carried out with DMC by Lantmäteriet can be used to accurately estimate tree height, stem volume and basal area for forest management planning, and also provide speciesspecific estimations of stem volume. Estimation was made using only remote sensing data already available, to a very low cost, in combination with a field sample of reference plots. a)

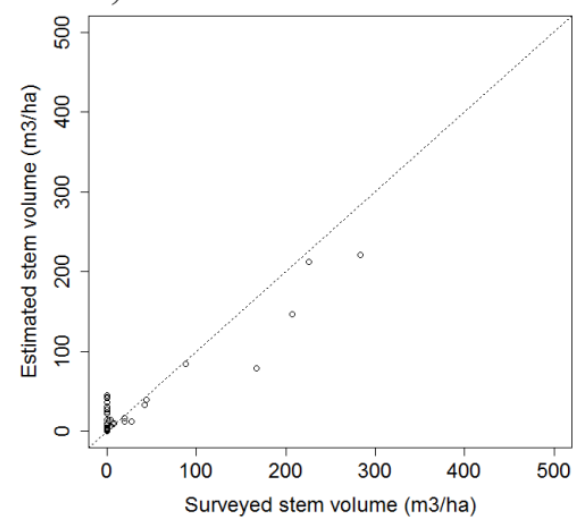

b)

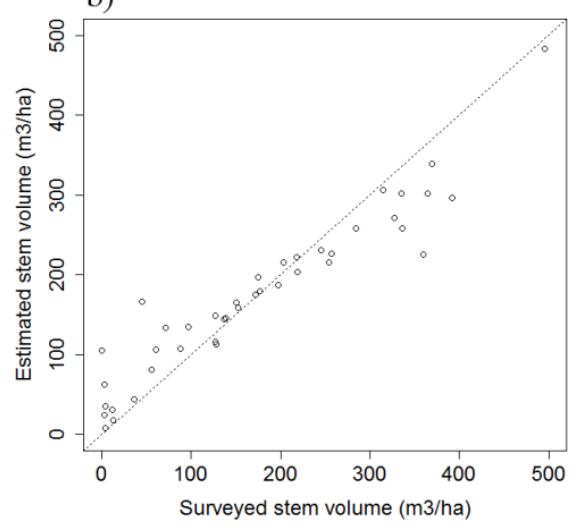

c)

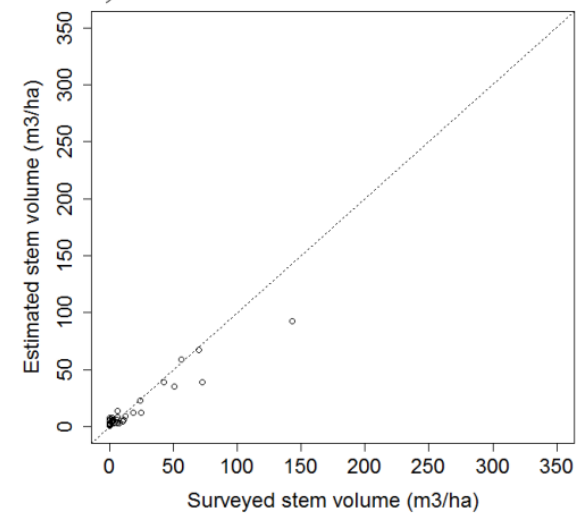

d)

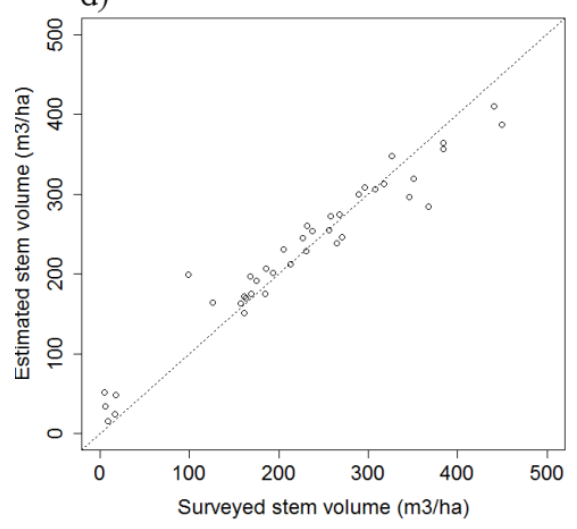

Figure 2. Estimated and surveyed stand mean stem volume, for pine $(a)$, spruce $(b)$, deciduous $(c)$, and total volume $(d)$. 
At stand level, the accuracy obtained here were 7.4\% RMSE (in percent of the surveyed mean) for tree height, $13.2 \%$ for stem volume and $11.4 \%$ for basal area. These accuracies are higher, or in agreement with, results from previous studies using other operational techniques or methods for forest management planning data acquisition, such as ALS-based and subjective field methods (e.g., Ståhl, 1998; Næsset et al., 2004; Bohlin et al., 2012). Furthermore, the species-specific volume estimates showed marginally lower absolute accuracy compared to Packalén and Maltamo (2007) for spruce, but similar for pine and deciduous volume. Measured in relative terms, the results are not as comparable, though, but probably due to the large differences in field sampled mean values. Furthermore, this pilot study was carried out using a simplified framework compared to the thorough study performed by Packalén et al. (2009). Here, estimation was performed using imputation, as a means to preserve the natural dependencies between estimated variables. That is, $k$-MSN was applied using $k=1$ rather than a larger value of $k$, which is expected to produce more accurate results. On the other hand, in order to limit the analysis, accuracy was here assessed without cross-validation, which is expected to underestimate errors. Further differences are the limited image data utilized here; only one flight strip of images was used due to the concentrated sampling design of the field plots, providing only little data from multiple overlapping images, and the fact that these images were also spectrally adjusted by Lantmäteriet. These facts are possible causes of reduced species classification accuracy compared to the results reported by Packalén and Maltamo (2007). Finally, the dataset was heavily dominated by spruce forest, probably with insufficient variation in species compositions to accurately estimate species-specific forest variables.

\subsection{Conclusions}

Stereo matching of images from the standard aerial mapping of Sweden provided estimates of tree height, stem volume and basal area with higher accuracy than data commonly used for forest management planning. Observed accuracies were similar to those obtained with methods using ALS and aerial images, but to a small fraction of those costs. The results imply that photogrammetric matching of digital aerial images has significant potential for operational use in forestry.

\section{References}

Anon., 2011. ApplicationMaster V 5.3 Reference Manual. INPHO GmbH, Stuttgart, Germany.

Axelsson, P., 1999. Processing of laser scanner data algorithms and applications. ISPRS Journal of Photogrammetry and Remote Sensing, 54, 138-147.

Axelsson, P., 2000. DEM generation from laser scanner data using adaptive TIN models. International Archives of Photogrammetry and Remote Sensing, 33, 110-117.

Bohlin, J., Wallerman, J. and Fransson, J. E. S., 2012. Forest variable estimation using photogrammetric matching of digital aerial images in combination with a high resolution DEM. Scandinavian Journal of Forest Research, in press.
Hinz, A., Dörstel, C. and Heier, H., 2001. DMC - The digital sensor technology of Z/I imaging. Photogrammetric Week 2001, Eds D. Fritsch/ R. Spiller, (pp. 93-103), Heidelberg, Germany: Wichmann Verlag.

Jonsson, B., Jacobsson, J. \& Kallur, H., 1993. The forest management planning package. Theory and application. Studia Forestalia Suecica, 189, 56 p.

Lemaire, C., 2008. Aspects of the DSM production with high resolution images, Proceedings of the ISPRS Congress, Commission IV, WG IV/9, Beijing/China, International Archives of Photogrammetry and Remote Sensing, Vol. XXXVII, Part B4, pp. 1143-1146. ISSN 1682-1750.

Magnussen, S. and Boudewyn, P., 1998. Derivations of stand heights from airborne laser scanner data with canopy-based quantile estimators. Canadian Journal of Forest Research, 28 (7), 1016-1031.

McGaughey, R. J., 2012. FUSION/LDV: Software for LIDAR data analysis and visualization. FUSION version 3.01. United States Department of Agriculture, Forest Service.

McRoberts, R. E., Cohen, W. B., Næsset, E., Stehman, S. T. and Tomppo, E. O., 2010. Using remotely sensed data to construct and assess forest attribute maps and related spatial products. Scandinavian Journal of Forest Research, 25 (4), 340367.

Næsset, E., 2002a. Determination of mean tree height of forest stands by digital photogrammetry. Scandinavian Journal of Forest Research, 17 (5), 446-459.

Næsset, E., 2002b. Predicting forest stand characteristics with airborne scanning laser using a practical two-stage procedure and field data. Remote Sensing of Environment, 80 (1), 88-99.

Næsset, E., Gobakken, T., Holmgren, J., Hyyppa, H., Hyyppa, J., Maltamo, M., et al., 2004. Laser scanning of forest resources: The Nordic experience. Scandinavian Journal of Forest Research, 19 (6), 482-499.

Packalén, P. and Maltamo, M., 2007. The k-MSN method for the prediction of species-specific stand attributes using airborne laser scanning and aerial photographs. Remote Sensing of Environment, 109, 328-441.

Packalén, P., Suvanto, A. and Maltamo, M., 2009. A two stage method to estimate species-specific growing stock. Photogrammetric Engineering \& Remote Sensing, Vol. 75, No. 12, pp. 1451-1460.

R Development Core Team., 2010. R: A language and environment for statistical computing. Vienna, Austria. Available from http://www.R-project.org/ (ISBN 3-900051-07$0)$.

Söderberg,U., 1986. Functions for forcasting of timber yeilds Increment and form height for individual trees of native species of Sweden. Swedish University of Agricultural Sciences, Department of Biometry and Forest Management, Umeå, Sweden, Report 14. 251 pp. (In Swedish with English summary). 
Söderberg, U., 1992. Functions for forest management. Height, form height and bark thickness of individual trees. Swedish University of Agricultural Sciences, Department of Forest Survey, Umeå, Sweden, Report 52. 87 pp. (In Swedish with English summary).

Soininen, A., 2004. TerraScan for MicroStation, User's Guide. Terrasolid Ltd., Jyvaskyla, Finland. 132 p.

Ståhl, G., 1988. Noggrannheten i skogliga data insamlade med subjektiva inventeringsmetoder [Accuracy in forest data captured with subjective inventory methods]. Swedish University of Agricultural Sciences, Department of Biometry and Forest Management, Umeå, Sweden, Report. (In Swedish).

Ståhl, G., 1992. A study on the quality of compartmentwise forest data acquired by subjective inventory methods. Licentiate thesis. report 24, Swedish University of Agricultural Sciences, Department of Biometry and Forest Management, Umeå, Sweden. (in Swedish with English summary). 